\title{
POLÍTICA EDUCACIONAL, JUSTIÇA DISTRIBUTIVA E EQUIDADE: CONSIDERAÇÕES SOBRE AS POLÍTICAS COMPENSATÓRIAS PARA A EDUCAÇÃO
}

\author{
Sandra A. Riscal \\ Universidade Federal de São Carlos -UFSCAR \\ riscal@uol.com.br
}

\section{RESUMO}

O presente artigo tem como objetivo o exame das concepções de equidade e justiça social que justificam as políticas compensatórias desenvolvidas por meio de projetos e programas do Ministério da Educação brasileiro a partir de 1995. Para tanto procuraremos estabelecer o papel das idéias de John Rawls na formulação dessas políticas destacando, em particular os conceitos de equidade e justiça distributiva desenvolvidos em sua obra. Finalmente procurou-se estabelecer a articulação entre as políticas compensatórias, a concepção gerencial de educação e de desenvolvimento econômico.

Palavras-chave: equidade; justiça distributiva; gestão educacional

\section{EDUCATIONAL POLITICS, DISTRIBUTIVE JUSTICE AND EQUITY: CONSIDERATIONS ABOUT COMPENSATORY POLICIES FOR EDUCATION}

\begin{abstract}
ABSTRAT
This article aims to examine the concept of equity and social justice that justify the compensatory policies developed through projects and programs by brazilian Ministry of Education since 1995. For this endeavor, we intent to establish the role of John Rawls in the formulation of these policies highlighting in particular the concepts of equity and distributive justice which are developed in his work. At last we pretend to establish the articulation between the compensatory policies, educational management conception and economics development.
\end{abstract}

Keywords: equity; distributive justice; educational management

\section{Introdução}

Este artigo tem o propósito de examinar alguns aspectos das formulações produzidas no campo da política educacional brasileira, a partir de 1995, que tratam de ações compensatórias. Tomando como ponto de partida as concepções de equidade e justiça distributiva de John Rawls, pretende-se compreender em que medida estas noções tem fundamentado as ações redistributivas que tem caracterizado os projetos e programas implementados no campo da educação nacional. Outro aspecto tratado neste estudo é a articulação entre a concepção de equidade, tal como é apresentada nos compromissos firmados com as agencias internacionais e a introdução de um tipo de racionalidade administrativa de caráter gerencial que vem orientado as estratégias de políticas publicas do Estado brasileiro desde meados da década de 1990. 
Para que se possa estabelecer o campo teórico em que se situam os documentos governamentais aqui estudados, iniciamos este artigo com alguns parágrafos dedicados à elucidação da particular acepção de equidade que caracteriza o discurso oficial. Para melhor estabelecer-se a origem, contexto e amplitude do discurso sobre a equidade, que se encontra nessa documentação, são abordadas, no item seguinte, as concepções de equidade e justiça distributiva na obra de John Rawls e sua repercussão nas políticas públicas brasileiras. A partir desta base conceitual, procurar-se-á compreender o caráter das concepções de justiça distributiva e das ações compensatórias implementadas por meio das políticas públicas brasileiras a partir da década de 1990. Finalmente, no último item, é apresentada uma breve discussão sobre o significado das ações compensatórias na educação brasileira.

\section{A concepção de equidade nos documentos oficiais brasileiros}

Um primeiro passo se faz necessário, antes de abordar-se diretamente o tema aqui proposto. É importante, para o prosseguimento da tarefa proposta: que se esclareça a concepção de equidade de que se trata neste estudo. Não se pretende aqui apresentar um estudo do conceito de equidade em suas diferentes fontes e acepções, nem tratar de sua gênese ou evolução história na filosofia moral e política. Trataremos, de forma sumária, da concepção de equidade tal como é apresentada nos textos e programas oficiais do Ministério da Educação, onde ocupa lugar de destaque, como se pode verificar no PAR (Plano de Ações Articuladas), no PDE (Plano de Desenvolvimento da Educação) e ou nos programas e compromissos propostos por agencias e instituições internacionais. Estes documentos vem induzindo um tipo de política educacional com base na otimização e eficiência do uso dos recursos públicos, que privilegiam o financiamento de projetos voltados para setores sociais considerados desprivilegiados.

Trata-se de uma concepção de equidade que se distingue de uma concepção de direitos universais plenos, que implicaria em uma distribuição igual dos recursos para todos. No caso da educação, a universalização do ensino, segundo esta ótica de equidade, não se realizaria por meio de uma política igualitária para todos, mas por meio de uma política de ajustes, que visa alocar mais recursos para quem tem menos. Isto significa que se o Estado não possui recursos para o financiamento de uma educação publica e gratuita para toda a população, na faixa etária adequada ou não de estudo, os recursos disponíveis devem ser empregados prioritariamente para o atendimento daqueles que se encontram em pior condições de atendimento. Trata-se de uma forma de ação política que não atua contra os privilégios, mas cria uma forma de privilégio negativo ou de discriminação positiva, como às vezes é denominada.

A concepção de equidade, tal como vem sendo empregada nos documentos oficiais, tem como base a idéia de que é necessário que se corrija os investimentos, que devem ser aplicados em maior grau para quem se encontra em maior grau de vulnerabilidade. Esta concepção realiza-se por meio do estabelecimento de indicadores que tem por finalidade apresentar os setores mais deficientes e que exigiriam, para que alcançassem um desenvolvimento semelhante aos demais setores da população, de uma alocação maior de recursos.

A ampliação do acesso a educação para a maioria da população, nas últimas décadas, apresentou resultados díspares no que se refere ao desempenho escolar dos diferentes grupos sociais. Isto permitiu que se concluísse que a igualdade social não poderia ser alcançada por meio da garantia meramente legal de chances iguais de acesso aos recursos públicos. Articulada à concepção de justiça social, a concepção de equidade 
passou a ser concebida como resposta racional para esse dilema, porque permitiria a compensação das desigualdades por meio da alocação pontual de recursos. Sob essa ótica, a igualdade social poderia ser alcançada por meio da correção de caráter compensatório, que garantiria não a igualdade na distribuição dos recursos públicos a toda a população, mas a redistribuição de forma a garantir o mesmo resultados a todos.

De acordo com essa concepção, a igualdade não se dá, portanto, na entrada, mas na saída do sistema. Na verdade, este sistema pode ser concebido não como uma reforma educacional, mas como uma reforma gerencial, porque atinge basicamente o sistema de financiamento da educação. A política educacional passa a assumir o aspecto gerencial e volta-se para a redução das desigualdades regionais e locais e para a equalização dos resultados. Todo o sistema educacional é redesenhado visando uma maior eficiência. Como a meta é atingir as parcelas da população mais carentes, o gerenciamento incide apenas no setor publico e prioritariamente nas escolas e setores da população que tem apresentam os piores resultados na comparação nacional de desempenho. Entretanto, como se sabe, parte da população em idade escolar encontra-se fora do sistema publico, porque tem condições de pagar pelo ensino privado e freqüentar escolas que apresentam bom desempenho. Neste caso não há interferência estatal, porque se considera a qualidade da educação satisfatória. O resultado final é a ausência de uma política educacional única, que abarque todo o sistema. Desta forma, é mantida, senão reforçada, a divisão entre a educação dos setores privilegiados, que devem arcar com o financiamento de sua educação com seus próprios recursos, em escolas cada vez mais distantes do acesso da maioria da população, e os setores não privilegiados, que recebem a educação publica que visa uma igualdade que jamais será alcançada, porque coexistem sistemas diferentes, em uma política que lembra a concepção de iguais mas separados.

O que importa, nesta concepção, é que o resultado final seja equializado, e o equilíbrio social adquirido por meio da redistribuição dos recursos, que mantém, ao menos superficialmente, na população desprivilegiada, a ilusão de que recebeu algum tipo de privilégio, sem que jamais consiga atingir a igualdade plena.

Em documento do Conselho Estratégico de Informações da Cidade do Rio de Janeiro, denominado Eqüidade e eficiência na política educacional, de 2007, Marcelo Néri, chefe do Centro de Políticas Sociais do Instituto Brasileiro de Economia e da Escola de Pós-Graduação da Fundação Getúlio Vargas, do Rio de Janeiro, apresenta de forma exemplar a concepção de equidade adotada na política educacional que tem predominado no Brasil nos últimos anos. Néri apresenta o índice pró-pobre, principal indicador de uma política governamental pró-pobre, cuja finalidade seria utilizar de forma mais eficiente os recursos públicos beneficiando mais aos pobres do que aos não-pobres. Isso significaria que, com um custo fixo para o governo, a política pró-pobre alcançaria uma maior redução da pobreza, se comparada a uma situação em que todos se beneficiam igualmente da política. Segundo Néri, quanto maior for o respectivo indicador pró-pobre de uma dada política, maior será a capacidade de cada real alocado chegar aos pobres. O nível do indicador é zero quando cada real distribuído por cidadão não atinge pobre nenhum. Quando o indicador atinge o valor unitário, cada real tem a capacidade de chegar aos pobres, equivalendo a uma política universal que atinge uniformemente a todas as pessoas, sejam elas pobres, ricas, ou de classe média. Quando o indicador é maior do que Um, configura-se uma situação pró-pobre.

O índice pró-pobre aplicado por série escolar mostra que, quando se dá mais peso aos mais pobres, equivale a: 


\begin{tabular}{|l|l|l|l|l|l|}
\hline Creche & $\begin{array}{l}\text { Analfabetismo } \\
\text { de adultos }\end{array}$ & $\begin{array}{l}\text { Primeiro grau } \\
\text { Público regular }\end{array}$ & $\begin{array}{l}\text { Segundo grau } \\
\text { Público regular }\end{array}$ & $\begin{array}{l}\text { Terceiro grau } \\
\text { público }\end{array}$ & Pós-graduação \\
\hline 1,14 & 1,9 & 1,73 & 0,72 & 0,1 & 0 \\
\hline
\end{tabular}

Fonte:CEIRJ,2007

O índice, portanto, mostra como se distribuem os benefícios educacionais e quem se apropria dos investimentos públicos em educação, e serviria para nortear os locais onde a aplicação dos recursos públicos seria mais eficiente.

\section{3. $O$ conceito de equidade de John Raws}

A concepção de equidade como justiça distributiva freqüenta os textos de filosofia política desde as obras de Platão e Aristóteles. Trata-se, portanto, de um principio antigo que, a partir da obra de John Rawls, adquire um novo significado no que se refere à elaboração das políticas públicas contemporâneas. As teses de John Rawls, ${ }^{1}$ expostas em seu clássico livro A Theory of Justice, publicado em 1971, tiveram grande repercussão e iniciaram um ardoroso debate em torno de sua concepção de justiça social. As concepções de justiça distributiva e equidade de Rawls foram determinantes na implementação das políticas de ação afirmativa nos Estados Unidos a partir da década de 1970. No Brasil, inspirou, na década de 1990 os defensores da renda-mínima e das políticas de ações afirmativas.

A concepção de justiça como equidade de Rawls foi uma alternativa liberal ao neoliberalismo, opondo a este concepções que podem ser remontadas a pensadores da filosofia moral e liberalismo clássicos. Enquanto o neoliberalismo assenta suas bases no individualismo utilitarista, na livre concorrência econômica e na desregulamentação do mercado, elevando as diferenças sociais, a concepção de Rawls segue a tradição liberal da filosofia política que remete à justiça distributiva de Aristóteles e ao imperativo categórico kantiano, retomando o humanismo e tolerância de Rousseau e Locke contra o utilitarismo de Bentham. (Rawls, 1981, p.04)

Pode-se dizer, de uma forma geral, que o projeto de Rawls seria substituir a concepção pura e simples de igualdade social pela de equidade, concebida como justiça distributiva. Isto significa que, se a concepção de igualdade supõe que todos sejam iguais, segundo um determinado enunciado, a equidade pressupõe que desigualdades existam e que devem ser levadas em conta para que uma relação de igualdade final seja alcançada.

Tradicionalmente, a concepção liberal de igualdade era definida como igualdade de oportunidades e direitos. Para Rawls, entretanto, essa concepção seria insuficiente, porque abordaria a igualdade do ponto de vista formal, por meio de sua garantia na lei. A equidade, por outro lado, consistiria em um processo que se desenvolve por um determinado período de tempo e que pressupõe projetos de ação social com a finalidade de restituir ou instituir a condição de igualdade para aqueles que se encontram em condições sociais desprivilegiadas. Trata-se de um projeto que tem como objetivo equalizar as condições sociais que se encontram originalmente em condições diferentes. Nesta perspectiva, considerar a todos como iguais significaria tratar desigualmente, de forma inversa, privilegiando aqueles que se encontrariam em posições desfavorecidas. Estamos diante de uma reinvenção da concepção de justiça distributiva, que consistiria de um processo racional de distribuição dos recursos proporcionais às necessidades. A concepção de Rawls implica, portanto, no emprego de mais recursos para os grupos mais vulneráveis e apresenta um aspecto importante. Ela parte do principio que a igualdade de oportunidades deve ser estabelecida de tal forma que a origem social ou econômica não afete a possibilidade de acesso aos bens sociais, como a educação. Daí a necessidade de 
uma justiça distributiva, que possibilite a superação das desigualdades e que assumiria a forma de uma discriminação positiva.

Carvalho observa que a concepção de Rawls permitiria, por meio das ações afirmativas, criar condições sociais nas quais os menos favorecidos possam trilhar e galgar espaços de ascensão socioeconômica e cultural:

A arquitetura teórica de Rawls pressupõe uma situação na qual políticas de compensação social seriam implementadas, com o claro objetivo de criar condições sistêmicas para que os grupos desfavorecidos - no caso, os negros norte-americanos -tivessem acesso aos empregos públicos e às vagas nos cursos universitários. Trata-se, sob a perspectiva liberal, tornar eficientes, sob o ponto de vista econômico, os membros dos grupos socialmente excluídos, levando a uma situação sustentável de bem-estar socioeconômico e cultural e de extensão de direitos de forma também ampliada e crescente. (CARVALHO, 2011, 18)

Para que possamos compreender a concepção de equidade de Rawls e o seu papel na elaboração de projetos compensatórios, dedicaremos alguns parágrafos para uma breve exposição de suas mais importantes idéias. A concepção de Rawls parte do princípio de que todos têm direito ao acesso aos bens primários básicos, coisas que os cidadãos precisam como pessoas livres e iguais para uma vida plena.(Rawls, 2003, p.81) .

Bens primários são, portanto, aquilo que as pessoas livres e iguais (...) precisam como cidadãos. Esses bens fazem parte de uma concepção parcial de bem com que cidadãos, que afirmam uma pluralidade de doutrinas abrangentes conflitantes, podem concordar com o propósito de fazer as comparações interpessoais necessárias para que haja princípios políticos exeqüíveis. (RAWLS, 2003, 85)

Rawls denomina situação de desvantagem a restrição ao acesso aos bens primários básicos. Essa condição exige uma ação que estabeleça o equilíbrio na estrutura social, por meio da justiça distributiva. Por isso estabelece os seguintes princípios:

a) cada pessoa deve ter um direito igual ao mais abrangente sistema de liberdades básicas que seja compatível com um sistema semelhante de liberdade para as outras.

b) as desigualdades sociais e econômicas devem ser ordenadas de tal modo que sejam ao mesmo tempo (b1)consideradas como vantajosas para todos dentro dos limites do razoável, e (b2) vinculadas a posições e cargos acessíveis a todos. (RAWLS, 2004, 64)

A formulação da teoria da justiça, apresentada por Raws, parte da concepção de um hipotético contrato social originário, que colocaria a todos em uma situação eqüitativa, onde desapareceriam as diferenças e desigualdades. Essa posição original é denominada de véu da ignorância e se assemelha à concepção de comunidade ideal de comunicação de Habermas. Esta posição inicial garantiria a imparcialidade e equidade por meio de um acordo que colocaria a todos distantes dos interesses individuais, por que cada um, nesta condição, não sabe se possui riquezas ou não, se tem poder político ou social, se é livre ou escravo. Nesta circunstância todos lutarão pelo benefício de todos (justice as fairness) ${ }^{2}$.

Trata-se de um reedição do imperativo categórico de $\mathrm{Kant}^{3}$ : age só segundo máxima tal que possas ao mesmo tempo querer que ela se torne lei universal. (Kant 2004, 
p.51) ${ }^{4}$ Segundo esta proposição, o dever de agir (imperativo) existe somente quando nossa máxima pode ser convertida em lei universal (incondicionada). Trata-se, portanto de uma ação que só é condicionada pelo próprio dever moral, universal, impessoal e sem interesse (prazer, reconhecimento, utilidade etc). Da mesma forma que o imperativo categórico kantiano, o véu da ignorância levaria a todos a adotarem princípios que limitariam as desigualdades em nome da igualdade de oportunidade para todos. Esta concepção fundamentaria as instituições básicas da sociedade que são responsáveis pela distribuição e regulação dos bens primários básicos.

O pensador belga Philipe Van Parijs, da Universidade de Lovain, um dos maiores especialistas em renda mínima e cujos trabalhos tiveram grande repercussão entre os estudiosos desta área no Brasil, aprofundou algumas das principias concepções de Rawls. Van Parijs desenvolveu suas concepções em torno do princípio básico segundo o qual a primeira prioridade da sociedade seria a igualdade equiitativa, isto é a igualdade de oportunidades e em seguida assegurar-se que as desigualdades em uma sociedade apenas se justificam quando beneficiem aos menos beneficiados. (Van Parijs, 1997,70) Isto significa que se deve dedicar os maiores recursos aos setores menos favorecidos. Para que se estabeleça uma ordem social justa, não bastaria uma divisão a igual de riquezas entre todos, mas seria necessária uma distribuição desigual para que se equalize socialmente os menos favorecidos. Disto resulta que a concepção liberal clássica de igualdades de oportunidades seria apenas um principio formal que, para ser realizado, exigiria um tratamento que beneficiaria aos menos favorecidos, sob o risco de se perpetuar ou ressaltar as desigualdades.

\section{Justiça distributiva e políticas compensatórias}

Um dos primeiros programas a adotar a perspectiva de justiça eqüitativa de Rawls, no Brasil, o renda-minima do senador Suplicy de 1992, foi inspirado na concepção de renda básica de Van Parjis. (Suplicy, 2001). ${ }^{5}$ Os projetos de renda mínima surgem dos estudos sobre a "alocação"universal" como enfrentamento do desemprego e pobreza provocados pela crise da economia capitalista européia e decadência do modelo de estadode-bem-estar social na década de 1980. Em seu sentido original, o termo alocação universal corresponderia a uma renda atribuída, incondicionalmente a todo cidadão e teria como objetivo constituir uma rede de proteção de direitos de seguridade social abaixo do qual nenhum cidadão poderia se situar.(Van Parijs, 2006, p.35) O conceito de alocação universal levou a elaboração de uma outra concepção similar, a "renda básica de cidadania”, uma renda paga por uma comunidade política a todos os seus membros, em termos individuais, sem comprovação de renda nem exigência de contrapartida."(Van Parijs, 2006, p.35). Essa concepção tem como principio fundamental o fato de que todo o cidadão tem o direito a uma renda mínima que deve ser garantida pelo Estado, demonstre ele necessidade ou não.

Associada à concepção de justiça eqüitativa, a concepção de renda básica de cidadania possibilita a elaboração do conceito de renda mínima como imposto negativo. $\mathrm{O}$ imposto negativo baseia-se na concepção de que se pode determinar um nível de pobreza, que constitui um patamar abaixo do qual nenhum cidadão pode viver dignamente. Seguindo os princípios da justiça eqüitativa, o imposto negativo seria uma forma de redistribuição de renda. Esta redistribuição seria feita a partir da arrecadação do imposto de renda que passa a ser redistribuído diretamente por meio de um pagamento pecuniário às pessoas que se encontram abaixo da linha da pobreza. Não se trata de um atendimento de serviços públicos, mas de um montante pago em dinheiro diretamente aos beneficiados. 
No Brasil este tipo de auxilio assume a sua forma definitiva em 2004, quando é criado o programa Bolsa Família, que atrelou o recebimento de benefício à frequiência escolar, com o intuído de estabelecer um processo de inclusão social. Seu publico alvo são as famílias em situação de extrema pobreza. O objetivo seria melhorar a possibilidade de inserção no mercado de trabalho. Trata-se de um programa que visa o combate à pobreza, a miséria e a exclusão social, a melhoria da auto-estima e garantir o exercício pleno da cidadania. Como se pode ver, estas são condições que podem ser descritas nos mesmos termos dos princípios sociais básicos de Rawls.

O programa Bolsa Família foi constituído por meio da unificação de uma série de outros programas sociais, incluindo o Bolsa-escola, originalmente instituído no governo de Fernando Henrique Cardoso e atingiu tal importância que, em 2003, o governo chegou a pensar em substituir um aumento extra do salário mínimo pela elevação do pagamento deste benefício ${ }^{6}$. Sua concepção de justiça é distributiva, no sentido definido por Rawls, e se apresenta na forma de imposto negativo. Constitui uma forma de política compensatória focal, voltada para a correção das injustiças sociais de uma parcela da população, considerada em condição de vulnerabilidade.

Um dos principais aspectos das políticas compensatórias é o fato de constituírem ações pontuais ou focais, voltadas apenas para populações ou setores considerados socialmente vulneráveis. É interessante observar-se que a concepção de vulnerabilidade social passou a freqüentar os documentos oficiais em substituição ao conceito de exclusão social, que antes designava a população que não tinha acesso pleno aos benefícios sociais. A mudança de nomenclatura não é sem significado e denota uma mudança na própria concepção de políticas públicas. Enquanto o conceito de exclusão apresenta, de forma inequívoca, a impossibilidade de acesso aos benefícios sociais e o exílio de uma parcela da população do exercício pleno da cidadania, a concepção de vulnerabilidade apresenta um aspecto mais matizado, onde o aspecto de exclusão é abandonado e substituído pela idéia de que essa população estaria momentaneamente desassistida ou a mercê de fatores negativos que, ao serem excluídos, permitiriam o retorno à plena fruição dos benefícios sociais.

Essa nova concepção é apresentada no documento Aspectos conceituais da vulnerabilidade social - um estudo resultante do Convênio MTE (Ministério do Trabalho e Emprego) e DIEESE de 2007 da forma que se segue: A vulnerabilidade é definida por critérios específicos, que podem mudar de acordo com as condições sociais, econômicas ou políticas e tem como um de seus objetivos a elaboração de indicadores que possam expressar as situações de vulnerabilidade social. A construção deste indicador permite explicitar com maior detalhe diferentes aspectos como locais, regiões, faixas etárias, raça, gênero, etc, em que essa vulnerabilidade se acentua permitindo o seu acompanhamento em séries históricas. É sem dúvida um elemento criado apropriadamente para avaliações de resultados de políticas públicas. O termo vulnerabilidade social, serviu inicialmente para a caracterização de situações sociais limites, de pobreza ou marginalidade, para, posteriormente permitir a formulação de políticas publicas. O documento torna evidente que a escolha da concepção de vulnerabilidade ocorreu porque teria maior poder explicativo para os estudos voltados para o mercado de trabalho frente a um quadro cada vez mais complexo das situações de precarização existentes.

Um dos principais suportes das ações compensatórias é a produção de indicadores estatísticos, capazes de estabelecer quais são os setores menos favorecidos e os campos de ações onde o investimento seria mais eficiente na redução das desigualdades. A produção dos indicadores sociais é a principal fonte para o estabelecimento das políticas a serem 
adotadas e que se constituem por meio de mecanismos compensatórios cuja finalidade é reparar, pela lei, as injustiças sociais constatadas.

Um dos maiores problemas que se impõe às políticas sociais é a quantidade limitada de recursos, que impede a sua igual distribuição para todos. Por isso, a concepção de equidade e justiça social, tal como foi pensada por Rawls, é também uma política voltada para retirar o máximo benefício dos recursos existentes, obedecendo aos princípios de eficiência e otimização. Embora a concepção de equidade implique nas mesmas oportunidades a todos os cidadão, para que esta condição se realize são necessárias ações compensatórias que exigem a suspensão temporária dos direitos iguais de todos, impondo tratamento desigual para os que estão em condições de desvantagem. A equidade exigiria, assim, uma contraposição à discriminação existente, estabelecendo uma discriminação no sentido oposto. A equidade se realiza, portanto, por meio de uma discriminação positiva e é conduzida como ação focal para redução das grandes desigualdades verificadas entre diferentes grupos populacionais. Trata-se de um processo que se inicia com o reconhecimento de manifestações de condições diferentes, que exigem uma adequação do atendimento em cada caso, de forma a se constituir um padrão de atendimento equânime. Assim, o problema dos recursos limitados acaba por impor uma racionalização em sua distribuição que passa a ser definida a partir da elaboração de indicadores que permitam estabelecer como melhor maximizar os recursos.

\section{Políticas compensatórias e política educacional brasileira}

As ações de caráter eqüitativo têm caracterizado as reformas educacionais que vem sendo adotadas no Brasil desde a década de 1990. Uma das características fundamentais do conceito de equidade é a universalização do acesso aos serviços públicos. Entretanto, a imposição do princípio de otimização de recursos e de justiça distributiva impõem ao Estado priorizar o acesso à educação pública àqueles que não tem condições de fazê-lo de outra forma. $\mathrm{O}$ acesso gratuito à educação deixa de ser um direito para todos por meio de uma espécie de engenharia social reversa que lhe imprimiu o aspecto de serviço. A lógica aqui imposta é a da racionalização econômica: o Estado deve arcar apenas com a educação daqueles que não poderiam fazê-lo por si só. Aos demais, cabe ao Estado apenas a regulação, que deve garantir a todos a oportunidade de acesso. A implementação de políticas baseadas na equidade implica, portanto, na definição de campos específicos e delimitados de atuação articuladas com a alocação de recursos.

No Brasil a incorporação dos princípios de equidade e de justiça eqüitativa nas políticas públicas, foi, desde o início, diretamente vinculada à concepção de desenvolvimento econômico, entendido como diminuição das diferenças por meio da elevação da capacidade de empregabilidade da população. Por esse motivo, os projetos educacionais tem sido articulados com a política de estabilidade e crescimento da economia.

A educação técnica e profissional é considerada, pelos agentes econômicos dominantes, fundamental para enfrentar a condição de vulnerabilidade externa. A formação de profissionais qualificados em áreas de maior pobreza, por meio de uma política de desenvolvimento regional, possibilitaria, segundo este ponto de vista, às regiões não industrializadas, o desenvolvimento de mão de obra qualificada e consequentemente a recepção de investimentos industriais que vinham se concentrando em regiões de maior concentração de riquezas.

A mudança processada na concepção de políticas públicas promovida pela incorporação da concepção de justiça distributiva, promoveu, também, uma alteração na 
noção de democratização, que deixou de representar o poder da população na determinação das políticas fundamentais que constituem o Estado para ser identificada com controles democráticos de políticas de implementação e gestão, consideradas por meio de sua maior eficácia em garantir a sustentabilidade da economia e não em seu papel de propiciar a redistribuição das condições de produção de renda.

A adoção de políticas de equidade teve início no primeiro mandato do presidente Fernando Henrique Cardoso e proliferou no governo seguinte, tornando-se a principal forma de ação política durante o mandato do presidente Luiz Inácio Lula da Silva.

Pode-se encontrar, durante o governo de Lula da Silva, programas que promovem a justiça distributiva em todas as áreas sociais: assistência, saúde, trabalho, educação, e em todos os casos podem ser identificados inúmeros projetos voltados para a contenção da pobreza por meio de ações compensatórias. Entretanto, é no Ministério da Educação que se encontra de forma explicita a elevação da política compensatória à condição de política de Estado.

As ações que vem sendo implementadas no campo da educação encontram-se em perfeita sintonia com a orientação das agências multilaterais para os governos latinoamericanos que visam a transformação produtiva com eqüidade e vem gradualmente assumindo papel central na política educacional porque privilegiam a articulação das atividades educativas com o desenvolvimento econômico e a empregabilidade.

A concepção de ações compensatórias e supletivas voltadas para a equidade social passa a ser objeto da política educacional a partir das orientações traçadas para a educação dos países mais pobres do mundo na Conferência Mundial sobre Educação para Todos, realizada em Jomtien, em março de 1990. Nesta conferência, os países signatários, entre eles o Brasil, assumiram o compromisso de desenvolver projetos voltados para a equidade e maximização dos recursos financeiros, orientados pela perspectiva dos quatro pilares da educação apresentados no Relatório Delors (1996).

O Fórum Mundial de Educação, realizado em Dakar em 2000 teve como principal objetivo avaliar os resultados do processo iniciado em Jontiem. Diante da dificuldade da maioria dos paises em atingir as metas propostas, novos compromissos foram firmados para o ano de 2015. Nos objetivos agora firmados é interessante destacar-se a necessidade de expandir e melhorar o cuidado e a educação de crianças em situação de maior vulnerabilidade.

Um dos aspectos mais importantes a ser ressaltado nestes compromissos refere-se ao fato de tratarem prioritariamente de políticas de gestão pública, voltadas não apenas para a educação, mas principalmente, para a equidade social, política e econômica. Embora tratem de princípios gerais para a educação, a ênfase dos compromissos é voltada para a necessidade de se produzir e integrar programas setoriais educativos e programas de geração de renda. Assessorias e recomendações são propostas com vistas à melhoria da gestão de programas, com investimento em novas tecnologias e ampliação da rede de apoio da esfera pública não-estatal .

A equidade é o pano de fundo sobre o qual se desenvolve o relatório denominado Educação um tesouro a descobrir, elaborado pela Comissão Internacional sobre Educação para o século XXI, presidida por Jacques Delors, em 1996 para a UNESCO. É a partir da concepção de justiça distributiva que se pode compreender as políticas de redução das desigualdades educacionais e sociais propostas no relatório. Na perspectiva da UNESCO, assim como nas demais agencias internacionais, a educação se apresenta como instrumento privilegiado para o crescimento econômico e para a ascensão social. É renovada aqui a antiga concepção de capital humano, que traz de volta a idéia de que o investimento na formação dos recursos humanos eleva a capacidade produtiva nacional. 
É possível identificar nas reformas da educação implementadas no Brasil, o papel central atribuído às políticas compensatórias e sua articulação com programas de gestão que visam a racionalização e maior eficiência no uso dos recursos públicos. Um dos primeiros programas, no campo educacional a promover a equidade associada a uma política de racionalização dos gastos públicos foi o FUNDEF. O Fundo de Manutenção $e$ Desenvolvimento do Ensino Fundamental e de Valorização do Magistério criado por meio da Lei n. 9.424/96 e seu sucessor, o FUNDEB possibilitam um melhor controle dos gastos públicos sobre a educação ao inaugurar a gestão de financiamento per capita associada a um programa de correção de desequilíbrios, por meio da redistribuição de impostos. $\mathrm{O}$ FUNDEF e FUNDEB são o resultado de uma política que, reconhecendo a falta dos recursos que permitiriam garantir o acesso ao ensino publico a todos aqueles que a ela teriam direito, teve que optar por uma solução gerencial, que possibilitasse baixar custos e centralizar o controle das políticas implementadas. Assim, as reformas que tiveram inicio com a io FUNDEF constituiriam, acima de tudo, novas formas de gerenciamento e controle dos gastos públicos na educação, buscando a maior eficiência com a maior cobertura.

Neste mesmo caminho de política de ações compensatórias e de equidade encontram-se o Programa Universidade para Todos, PROUNI, a UAB, Universidade Aberta do Brasil, que promove cursos de Universidades publicas federais por meio de educação a distância e uma série de programas menores do Ministério da Educação, voltados para política focais de raça, gênero, indígenas, educação no campo etc. Outros programas estão voltados para formação, em nível de extensão ou especialização, de gestores, coordenadores, professores de educação básica e infantil. São oferecidos ainda, nesta mesma perspectiva, cursos de extensão para gestores municipais, conselheiros municipais ou conselhos de escola que promovem a divulgação e asseguram a homogeneização das ações daqueles que são os responsáveis pelas aplicação desta políticas no âmbito dos municípios.

Outro programa que se enquadra na concepção de políticas compensatórias é o Plano de Ações Articuladas, que funciona como projeto de indução e avaliação das políticas de equidade que, estabelecidas pelo Ministério da Educação, no nível federal, devem ser implementadas nas esferas estadual e municipal. Para participar do PAR, o estado ou município deve aderir ao Compromisso: Todos Pela Educação, um programa de 28 diretrizes com metas de voltadas para a equidade e elevação do IDEB. Essas metas devem ser alcançadas em até quatro anos. Um diagnostico da educação local é realizado e formulado o PDE local (Plano de Desenvolvimento da Educação) mediante o qual o estado ou município recebem recursos e apoio técnico. Nas escolas e regiões diagnosticadas como mais criticas, são enviados consultores do MEC e apoio técnico por meio de uma parceria com 17 universidades públicas. O PAR acabou se tornando um importante mecanismo de redistribuição de verba do orçamento federal e, de acordo com dados publicados no site do MEC, todos os 5.563 municípios brasileiros estão comprometidos a realizar o Plano de Ações Articuladas.

A concepção compensatória, que visa redistribuir racionalmente os fundos públicos para a educação, tomando como critério as regiões menos favorecidas, é claramente apresentada no PDE, Plano de Desenvolvimento da Educação. A leitura deste documento permite compreender como são vinculadas as concepções de equidade, desenvolvimento econômico e uso racional dos recursos. No item em que são apresentadas as razões e princípios do PDE, pode-se ler que: 
Só é possível garantir o desenvolvimento nacional se a educação for alçada à condição de eixo estruturante da ação do Estado de forma a potencializar seus efeitos. Reduzir desigualdades sociais e regionais se traduz na equalização das oportunidades de acesso à educação de qualidade.

(MEC, PDE, 2007, p. 05)

É explicita, no texto, a vinculação entre desenvolvimento nacional e educação, que se torna, por esse motivo, estruturante da ação do Estado. A idéia de potencialização dos efeitos remete a concepção de otimização e permite compreender que à educação é atribuído o papel de potencializadora do desenvolvimento, concepção que traduz perfeitamente as orientações das agencias internacionais. Além disso, a equalização de oportunidades de acesso à educação é apresentada como processo idêntico à redução das desigualdades.

Pode-se ler no documento como é justificada a necessidade de criação do PDE :

A razão de ser do PDE está precisamente na necessidade de enfrentar estruturalmente a desigualdade de oportunidades educacionais. Reduzir desigualdades sociais e regionais, na educação, exige pensá-la no plano do País. O PDE pretende responder a esse desafio através de um acoplamento entre as dimensões educacional e territorial operado pelo conceito de arranjo educativo. Não é possível perseguir a eqüidade sem promover esse enlace. $\mathrm{O}$ enlace entre educação e desenvolvimento é essencial na medida em que é por meio dele que se visualizam e se constituem as interfaces entre a educação como um todo e as outras áreas de atuação do Estado. (MEC, PDE, 2007, p 06)

A introdução do conceito de arranjo educativo aponta para uma vinculação, ou como é apresentado no texto, um enlace, entre a educação e o desenvolvimento social, aspecto essencial para que se atinja a equidade. Isto significa que não se trata de traçar um programa nacional de educação, mas de se elaborar programas voltados para as especificidades territoriais que são definidas por meio das necessidades de desenvolvimento. É basicamente a desigualdade, em termos de desenvolvimento, que determina o tipo de enlace que se realizará localmente com a educação. Pode-se concluir que a educação pode ser considerada, neste caso, uma alavanca para o desenvolvimento regional, o que parece apontar para implementação de políticas de formação profissional, de emprego, produção industrial ou agrícola e elevação da capacidade de consumo e comércio. É interessante observar como a participação do Estado é apresentada como uma necessidade gerencial, que estabelece políticas públicas que potencializam os efeitos das diferentes ações que devem ser articuladas para maximizar os resultados e otimizar os recursos disponíveis.

Não importa a abrangência do território considerado, o bairro ou o país. A relação recíproca entre educação e desenvolvimento só se fixa quando as ações do Estado são alinhadas e os nexos entre elas são fortalecidos, potencializando seus efeitos mútuos.Desse movimento de busca de sintonia das políticas públicas entre si depende a potencialidade dos planos setoriais, inclusive o educacional, que passam, nesses termos, à condição de exigência do desenvolvimento econômico e social, garantindo-se que o todo seja maior que a soma das partes. (MEC, PDE, 2007, p. 06) 
Os Programas e planos do MEC, como o PAR e PDE, permitem que se compreenda a dimensão que as ações compensatórias vem assumindo na política educacional brasileira, não restringindo mais a ações laterais ou isoladas, tendo se tornado a própria definição de todas as políticas empreendidas no ministério.

\section{Considerações finais}

O exame das concepções de equidade e justiça distributiva, apresentados neste trabalho, permitiu que se constatasse que o direito de todos à educação, constitucionalmente estabelecido, assumiu um novo significado com a introdução das concepções de John Rawls. A necessidade de atendimento a todos e os escassos recursos reservados à educação determinaram uma política de distribuição racional dos recursos de forma a maximizar os resultados por meio de políticas compensatórias. Pretende-se, com a adoção dessa política, responder às críticas dirigidas, em particular pelas agencias multilaterais, que sempre apontaram o atendimento desigual da população brasileira. Essa situação vinha secularmente ampliando a desvantagem social da população mais pobre, deixando um grande contingente de pessoas fora do sistema produtivo e de consumo. As disparidades entre as regiões do país, além das diferenças de atendimento aos diferentes grupos de raça, gênero e classes sociais eram frequentemente apresentados como um obstáculo ao crescimento econômico nacional.

A adoção de uma política voltada para a equidade por meio de ações compensatórias permitiu que se realizasse a articulação entre as ações governamentais no âmbito da educação e o almejado desenvolvimento econômico. Embora travestido de equidade, pode-se constatar que o imperativo da política educacional permanece a formação para a empregabilidade. Tomadas nesta perspectivas, as políticas de caráter compensatório têm como resultado a incorporação ao mercado de trabalho de um contingente que antes destas ações se encontrava fora do campo produtivo, e que agora tem acesso a melhores condições de empregabilidade e de consumo. Ao final, pode-se concluir que, embora permitam a ascensão ao mercado de amplos setores antes dele excluídos, as ações compensatórias tem caráter paliativo e não visam à alteração do quadro de produção e de distribuição de riquezas, porque não eliminam as condições de privilégios. Permitem a ascensão ao mercado de um novo contingente de empregados e consumidores, impulsionando a economia sem jamais conseguir eliminar de fato as diferenças sociais.

\section{Referências:}

ABBAGNANO, N. Dicionário de Filosofia. São Paulo: Mestre Jou, 1970, p. 519.

BOLIVAR, A. Equidad Educativa y Teorías de la Justicia. Revista Electrónica Iberoamericana sobre Calidad, Eficacia y Cambio en Educación, 3(2), pp. 42-69. 2005. disponible em http://www.rinace.net/arts/vol3num2/art4_por.htm.

BRASIL Ministério da Educação, Plano de ações articuladas PAR in Portal do MEC, (acesso em 23/07/2011), disponível em:

http://portal.mec.gov.br/index.php?option=com content\&view=article\&id=159\&Itemid=369,

BRASIL, Ministério da Educação PDE Plano de desenvolvimneto da Educação, 2007. (acesso em 23/07/2011), disponível em http://portal.mec.gov.br/arquivos/livro/livro.pdf 
BRASIL, TEM (MINISTÉRIO DO TRABALHO E EMPREGO), Aspectos conceituais da vulnerabilidade social, Projeto de Qualificação Social para Atuação de Sujeitos ou Grupos Sociais na Negociação Coletiva e na Gestão de Políticas Públicas, Convênio MTE (ministério do trabalho e emprego) -DIEESE -2007, disponível em http://www.mte.gov.br/observatorio/sumario_2009_TEXTOV1.pdf. $\quad$ acesso em $\underline{17 / 07 / 2011 .}$.

CARVALHO, V. G. A idéia de justiça e a política de cotas raciais no Brasil: dilemas e perspecivas segundo o pensamento de John Rawls. in Dontotal.co. Revista de Direito, 02/2001 acesso 25/07/2011 . Disponível em http://www.domtotal.com/direito/uploads/pdf/6ce6c5de6d2af40b289ed14818e7aeb6.pdf,

FOLHA ON LINE Lula pode elevar Bolsa-Escola, e não mínimo. 03/02/2003. Disponível em <www1.folha.uol.com.br/folha/brasil/ult96u45563.shtml. (acesso em 29/10/2005).

GOYARD-FABRE, Simone, Filosofia crítica e razão jurídica, S.P.: Martins Fontes, 2006.

KANT, I. Fundamentação da Metafísica dos Costumes e Outros Escritos. São Paulo: Martin Claret, 2004

RAWLS, J. Uma teoria da justiça. Brasília: UNB, 1981 1992.

Justiça como Equidade: uma concepção política, não metafísica. Lua Nova, $\mathrm{n}^{\circ} 25$, Justiça como Equidade: uma reformulação. São Paulo: Martins Fontes, 2003. . O direito dos povos. São Paulo: Martins Fontes, 2004.

RIO DE JANEIRO Eqüidade e eficiência na política educacional - Apresentação de Marcelo Néri - chefe do Centro de Políticas Sociais do Instituto Brasileiro de Economia e da Escola de Pós-Graduação da Fundação Getúlio Vargas - ATA No. 46 /25 de Abril de 2007. disponível em http://www.rio.rj.gov.br/ipp/download/ata_25abr2007.pdf . acesso $25 / 11 / 2008$

SUPLICY, Eduardo Matarazzo. Renda de Cidadania. S.P.: Cortez Editora ; Ed. Fundação Perseu Abramo,2004.

UNESCO, Relatório Delors : Educação um tesouro a descobrir. 1996. disponível em: http://www.microeducacao.com.br/concurso/ConcursoPEBII2009/B-Delors-EducacaoUm\%20Tesouro\%20a\%20Descobrir.pdf. Acesso em 15/07/2011

UNESCO, Declaração mundial sobre educação para todos e plano de ação para satisfazer as necessidades básicas de aprendizagem. Nova York: UNESCO, 1990

Disponível em http://unesdoc.unesco.org/images/0008/000862/086291por.pdf (acesso em 29/10/2005)

VAN PARIJS, P. O que é uma sociedade justa? Introdução à prática da filosofia política. São Paulo: Ática, 1997.

VAN PARIJS, P. Renda Básica de Cidadania - argumentos éticos e econômicos. R.J:

Editora Civilização Brasileira, 2006. 
Notas

${ }^{1}$ John Rawls (1921 - 2002) foi um dos principais teóricos do liberalismo norte-americano da última metade do século passado. Foi professor de Filosofia Política na Universidade de Harvard, autor de Uma Teoria da Justiça (A Theory of Justice, 1971), Liberalismo Politico (Political Liberalism 1993), e O Direito dos Povos (The Law of Peoples 1999). Suas doutrinas tiveram grande influencia na implementação de políticas de ações afirmativas nos Estados Unidos.

${ }^{2}$ Príncipe of fairness, foi um conceito introduzido por Herbert L.A. Hart, jurista positivista de Oxford e siginificaria "respeito às regras do jogo" como base para um pacto social.Ver Rawls, 1981,p.03.

3 A dívida a Kant é amplamente reconhecida por Rawls que dedica um artigo, em 1975 a este tema: A kantian conception of equality, in Cambridge Review, feb. 1975, vol.96, no. 2225, pp94-99. Simone GoyardFabre observa que o kantismo de Rawls chega a ser obstinado e afirma que Rawls não tolera nenhuma negociação a esse respeito, em particular quanto a sua concepção de justiça como imperativo categórico do direito. Ver Simone Goyard-Fabre, Filosofia crítica e razão jurídica, S.P.: Martins Fontes, 2006.

${ }^{4}$ Kant em seu livro Fundamentação da Metafísica dos Costumes, de 1785 refere-se ao imperativo categórico como uma ordem da razão, isto é a representação de um princípio objetivo enquanto constrange a vontade. Abbagnano N. Dicionário de Filosofia. São Paulo: Mestre Jou, 1970, p. 519.

${ }^{5}$ O programa de renda mínima foi proposto pelo senador Eduardo Suplicy na forma de Projeto de Lei na Câmara dos Deputados no. 2.561, de 1992. Neste projeto é considerado como beneficiário o indivíduo em idade produtiva que encontra-se abaixo da linha de pobreza em decorrência de diversos fatores sóciopolíticos, como desemprego ou ainda que trabalhe, não consegue suprir as necessidades básicas familiares, Ver Suplicy, Renda de Cidadania. S.P.: Cortez Editora ; Ed. Fundação Perseu Abramo,2004.

${ }^{6}$ Folha on line, 03/02/2003 Lula pode elevar Bolsa-Escola, e não mínimo. Na reportagem do Jornal sobre o Orçamento da União para 2003, é afirmado que , entre as opções para corte de gatos na área social seria aumentar o valor da bolsa-escola e não ao salário mínimo. A tese era defendida por economistas ligados à equipe de governo e com apoio ministro do então ministro da educação Cristovam Buarque. Os argumentos em favor da bolsa-escola era que o valor do benefício custaria menos do que o reajuste extra (acima da inflação) do mínimo e porque seria mais eficaz no combate à pobreza, atingindo as crianças, onde se concentraria o maior grau de indigência enquanto a elevação do mínimo beneficiaria também os milhões de aposentados. Disponível em <www1.folha.uol.com.br/folha/brasil/ult96u45563.shtml>.

Recebido em: $\quad$ 08/08/11

Aprovado em: $18 / 09 / 11$ 